\title{
A RELEVÂNCIA DO PRINCÍPIO DA FRATERNIDADE EM TEMPOS DE CRISE
}

\author{
Fernando Gomes de Andrade ${ }^{1}$ \\ Ana Paula Cavalcante Luna de Andrade ${ }^{2}$ \\ DOI: https://doi.org/10.47306/978-65-88213-03-2.234-245
}

Sumário: 1 Introdução; 2 Considerações acerca do princípio da fraternidade; 3 Solidariedade e Fraternidade: uma distinção necessária?; $4 \mathrm{O}$ papel do princípio da fraternidade no contexto de crise, tragédias e rupturas; 5 Considerações finais; Referências.

\section{Introdução}

O individualismo vivenciado em âmbito global pela vida contemporânea não raras vezes coisifica as relações humanas pautando a interação entre as pessoas em um agir estratégico conducente a uma superficialidade relacional. A "normalidade" da vida cotidiana exige das pessoas ações quase automáticas nos diversos papéis desempenhados na sociedade. Em tempos de crise, tragédias ou rupturas, quando a zona de conforto parece não mais existir, o transe coletivo se desfaz e as pessoas percebem o real significado de seu próprio ser e da necessidade de ir ao encontro do outro. Há um abismo separando as pessoas sob diversos aspectos, quais sejam: financeiros, intelectuais, políticos, religiosos, filosóficos... mas quando tudo desmorona, percebe-se a essência, a pessoa humana.

$\mathrm{Na}$ tragédia, se não há universidade pouco importa diferenciar docente e discente; se não há bancos, bens ou um sistema financeiro organizado por causa de uma guerra, não mais nos distanciamos no binômio rico/pobre, somos todos iguais. Na pandemia atual imposta globalmente pelo novo coronavírus, não há vacina, tratamento eficaz que se possa comprar, nem mesmo estudos aprofundados, estamos todos na mesma condição.

\footnotetext{
${ }^{1}$ Doutor em Direito pela Universidade Clássica de Lisboa (FDUL). Mestre em Direito Público pela UFPE. Professor Adjunto na Universidade de Pernambuco (UPE) e no Centro Universitário Tabosa de Almeida (AscesUnita). Coordenador-Executivo do IEA da Asces-Unita. fernandoandrade@asces.edu.br.

${ }^{2}$ Doutoranda em Ciências da Religião pela UNICAP. Mestra em Filosofia pela UFPE. Professora na Universidade de Pernambuco (UPE) e no Centro Universitário Tabosa de Almeida (Asces-Unita). Pesquisadora do IEA AscesUnita e coordenadora pedagógica. analuna@asces.edu.br.
} 
Se a obviedade da igualdade da condição humana parece ofuscada pela "vida normal", nas crises, tragédias e rupturas percebe-se e volta-se o olhar para o semelhante que embora diferente em diversos aspectos é igual por natureza. Aflora o sentimento que somos todos irmãos e o cuidado com o outro emerge nestes momentos de caos.

A fraternidade é um princípio norteador em vários âmbitos, pode ser relacionada à política, saúde, economia, sociologia, filosofia, teologia, direito. Significa um passo além da solidariedade no reconhecimento recíproco entre pessoas livres e iguais, constitui-se em resposta para grandes dilemas na promoção do encontro.

O escopo do presente trabalho é discorrer acerca da relevância do princípio da fraternidade no contexto de crise e para tanto iniciaremos abordando algumas considerações sobre este princípio, a relevante distinção entre a solidariedade e fraternidade e o papel do princípio da fraternidade no contexto de crise, tragédias e rupturas.

Para este desiderato buscamos apoio na doutrina "fraternalista", fértil terreno acadêmico nestas discussões essenciais para a compreensão da sociedade atual, bem como exemplos concretos do agir fraterno em nível institucional exemplificado pela atuação de cada um dos Poderes da República brasileira em consonância com as respostas nas relações jurídicas horizontais dos cidadãos.

\section{Considerações acerca do princípio da fraternidade}

A relevância histórica da Fraternidade no mundo ocidental tem o seu ponto alto na Revolução Francesa ${ }^{3}$ que teve como lema a Liberdade, Igualdade e Fraternidade, nasce em contrapartida a uma sociedade profundamente marcada pela injustiça social e que tinha anseios de políticas e novos modelos que promovessem a justiça e a paz. (ANDRADE, 2018, p. 58).

A abordagem do tema "fraternidade" é delicada, pois o pesquisador deve, antes de tudo, conceituar e situar de forma clara o termo para evitar confusões e imprecisões terminológicas. É fato que a expressão tem origem cristã, Cox (2012, p. 158) entende que: "no núcleo mais forte do princípio da fraternidade está o ágape cristão: amor pelo próximo que prescinde toda noção de cálculo e reciprocidade", mas no mundo laicizado consta do tríptico revolucionário

\footnotetext{
${ }^{3}$ A Revolução Francesa foi um acontecimento apontado como um grande marco de entrada para o início da Idade Contemporânea, proclamando os princípios universais de "Liberdade, Igualdade e Fraternidade".
} 
francês do final do séc. XIX ao lado da liberdade e igualdade, deste modo, foi traduzido como categoria política e jurídica, a despeito do viés religioso.

A humanidade laica e politizada encontra na fraternidade construída e reconstruída ao longo do tempo e da história, um elemento potencializador e caracterizador da própria condição humana em sua dignidade intrínseca e natural. Os seres humanos devem promover a liberdade e a igualdade, pois são fraternos (irmãos).

O termo não está aprisionado como categoria religiosa, mas adentra no próprio reconhecimento humano. Veronese (2016, p. 19) fala em uma "pedagogia do reconhecimento". Em outras palavras, a liberdade e a igualdade teriam sua concretização dificultada, ou mesmo inviabilizada, sem o “espírito fraterno”, logo, a fraternidade é condição indispensável na relação com o outro. Cerviño (2012, p. 71) discorre:

Diante da tentação de ambos os princípios se desvirtuarem em egoísmo (o individualismo liberal e o coletivismo marxista), a fraternidade vem a ser aquele princípio que equilibra a liberdade e a igualdade, descentralizando-as e tornando-as complementares.

Até pouco tempo era um princípio esquecido. "Podemos afirmar que a fraternidade se perdeu no tempo, porque brotou num contexto sumamente racionalista, que anulou a dimensão religiosa do ser humano, ou, pelo menos, reduziu-a à esfera privada", explica Cerviño (2012, p. 73). De fato, da tríade revolucionária francesa, a liberdade e a igualdade revelaram e desenvolveram a racionalidade; a fraternidade resgata a aspecto humanístico, lembrando ao ser humano que ele deve transpor os limites da razão. Segundo Baggio (2011, p. 15), o conceito de fraternidade: "contém uma complexidade particular, devido ao fato de expressar uma relação de paridade entre dois sujeitos diferentes (...) a igualdade entre irmãos consiste na possibilidade de ser, cada um, livre na própria diversidade".

Concordamos com Barzotto (2018, p. 79) quando defende que a "fraternidade está ligada conceitualmente à ideia de dever"; um dever recíproco que vai e volta, um sair de si ao encontro do outro, algo que vai na contramão do individualismo e das ações estratégicas visando o autointeresse tão difundidas nos dias atuais em uma sociedade hedonista e exclusivista. Baggio (2009, p. 209) adverte que a relação fraterna "não é uma relação de troca, não está baseada sobre o valor do que se troca, pelo contrário, é uma relação de co-associação, fundada no valor intrínseco de existência de cada um".

O conceito de Fraternidade traz em si a potencialidade da plena cidadania entre os seres humanos, quando se reconhecem como iguais, irmãos, fraternos, que fazem parte de uma mesma família. Para Mardones (2010, p. 57), a fraternidade é “o cimento ou amálgama de uma 
comunidade política - local, nacional e/ou global - que se observa como confiança generalizada". Podemos apontar esta como uma dimensão da fraternidade que adentra no reconhecimento do outro por um ato de amor um ato de comunhão. Segundo Barzotto (2018, p. 79):

\begin{abstract}
A fraternidade é o modo próprio dos seres humanos viverem humanamente. Não há alternativas à fraternidade. Ao negar ao outro o reconhecimento de membro da família humana (irmão), nega-se a própria pertença à humanidade. A fraternidade é a expressão moral da verdade antropológica de que a vida plenamente humana é a vida com os outros e para os outros.
\end{abstract}

Quando tratamos alguém como irmão, quer dizer que tratamos o outro de igual para igual. Agindo assim nos aproximamos da regra de ouro descrita por Mahatma Gandhi: "A regra de ouro é ser amigo do mundo, é considerar 'uma só' toda a família humana”, portanto, a vivência da fraternidade possibilita ao ser humano buscar não só o seu próprio bem, mas o bem comum da sociedade.

O alicerce da Fraternidade é a pessoa, segundo Fiores (1989, p. 471) "como ser existente, a pessoa abriga em si princípio vital comum individualizado na identidade irrepetível de cada um. O respeito por esta individualidade e a solidariedade com tal comunidade são prérequisitos da fraternidade".

Ropelato (2008, p. 103) fala em fraternidade universal que pode ser compreendida como a união de relações de pertencimento recíproco e de responsabilidade, bem como no "respeito de cada uma das diferentes multiplicidades".

Nessa perspectiva a fraternidade retoma a sua proposta original e revolucionária de mudança e transformação social, e se efetiva quando encontra uma sociedade politicamente solidária, de indivíduos livres e iguais.

A palavra fraternidade contém na sua essência o sentido de corresponsabilidade, de interdependência e gera relacionamentos autênticos que possibilitam a concretização do bemcomum, de sentir-se partícipe da grande família humana, é voltada à construção do ut omnes no sentido do reconhecimento do outro que é diferente de mim, mas ao mesmo tempo igual a mim. Segundo Fiores (1989, p. 471) “A fraternidade é dado fundamental no componente ontológico do ser humano: o homem é irmão. Uma resposta às exigências da fraternidade equivale à própria pessoa humana". Segundo Vargas (2018, p. 9): "ser pessoa para experimentar a fraternidade, é ser ou estar em relação, uma relação que convida à reciprocidade". Rossetto (2017, p. 11) distinguindo alguns conceitos expõe que a relacionalidade propõe "um sentido de vínculo; a reciprocidade de agradecimento; a relacionalidade indica o outro onde eu miro e 
busco expressão; a reciprocidade trata da presença de ambos; a relacionalidade aponta para o céu; a reciprocidade para a terra de um e outro".

A vivência do concreto amor recíproco, reconhecer o outro como irmão, é a expressão humana do mais sincero desejo por união, do anseio de ver cair os muros que nos separam. “Chamar alguém de irmão supõe testemunho existencial visível, isto é, 'fraternidade' implica prodigalizar-se em favor de objetivos e conteúdos tangíveis" (FIORES, 1989, p. 468).

Para garantir um ambiente de Paz que contraponha as crises vividas pelo ser humano na atualidade, a fraternidade não pode ser vista apenas como um sentimento, mas um princípio norteador das relações humanas onde o bem comum perpasse na vivência, no agir de cada indivíduo e tenha como fim o bem-estar da coletividade.

Segundo Chiara Lubich (2001): “A fraternidade liberta cada homem das amarras que o prendem, das multiformes de subordinação e de escravidão, de qualquer relacionamento injusto, realizando, assim, uma autêntica revolução existencial, cultural e política”.

\section{Solidariedade e Fraternidade: uma distinção necessária?}

Termos muito próximos, mas que trazem diferenças importantes, são a solidariedade e a fraternidade. O preâmbulo da Constituição Federal brasileira principia o texto maior do país dispõe acerca da construção de uma sociedade fraterna e o artigo $3^{\circ}$ quando estabelece os objetivos da República Federativa do Brasil determina a construção de uma sociedade livre, justa e solidária. O preâmbulo tem caráter normativo, segundo Machado (2017). Ser solidário não é ser fraterno, por isso merece uma explicação mais profunda.

Inicialmente é importante ventilar que a fraternidade pressupõe a liberdade e a igualdade. Caso haja uma impossibilidade do interlocutor em exercer plenamente a sua liberdade será preciso uma ação solidária para emancipá-lo e depois estabelecer, na liberdade de todos, uma relação fraterna. Não há plena fraternidade se existe a priori uma hierarquização relacional, pois a igualdade também é condição sine qua non. Segundo Barzotto (2018, p. 86), na solidariedade: "trata-se de assumir a responsabilidade pelo outro para que este, no período mais breve possível, assuma a responsabilidade por si mesmo".

Logo, a solidariedade está ligada ao assistencialismo e, deste modo, a relação é verticalizada, pois há aquele que ajuda e o outro que é ajudado, denotando um sentimento de 
compaixão, a via é de mão única haja vista que não há reciprocidade, ao contrário, a unilateralidade é visível nos papéis desempenhados. Mardones (2012, p. 41) considera a solidariedade como um vínculo "guiado pela racionalidade e não pelos sentimentos, que interpela a prover ajuda e que descansa na similaridade de interesses e metas ainda que se mantenha a diferença entre os membros".

Citando Bayertz, Mardones (2012, p. 42) diferencia quatro expressões de solidariedade, quais sejam social, humana, política e cívica. Por solidariedade social compreende como o "grau de identificação mútua entre os membros de um grupo como resultado de uma história, consciência, localização ou experiência comuns". Em relação à solidariedade cívica é considerada a relação do Estado com o cidadão que é socorrido mediante uma política social. A solidariedade política ocorre quando um grupo se une em oposição a outro que titulariza o poder, ou seja, "gera um movimento social que une indivíduos a favor de uma causa contra as práticas e políticas que sustentam outro grupo" (Mardones, 2012, p. 42).

A solidariedade humana é aquilo capaz de vincular e reconhecer o outro como semelhante, pertencente ao gênero humano. Bento XVI afirma que: "A solidariedade consiste primariamente em que todos se sintam responsáveis por todos e, por conseguinte, não pode ser delegada só ao Estado".

$\mathrm{Na}$ fraternidade, as relações são horizontais e de mão dupla (bilateralidade). É possível que em determinados contextos seja preciso iniciar a experiência solidária e avançar na construção de uma sociedade fraterna.

A solidariedade seria o princípio de planificação social permitindo aos desiguais tornarem-se iguais, a fraternidade é o princípio que permite aos iguais serem pessoas diferentes pondo em comum suas potencialidades. A atitude fraterna gera uma relação fraterna, quando há aderência social e enraizamento cultural gera uma sociedade fraterna. Entretanto, ressaltamos que dificilmente a sociedade será fraterna sem que antes seja solidária, haja vista que a finalidade da solidariedade é a inclusão, e como bem expressa o Papa Francisco: "a falta de solidariedade é anestésica, adormece a pessoa em relação às necessidades do outro".

Na Carta Encíclica caritas in veritate, Bento XVI considera a fraternidade como "prática da caridade na verdade" na gratuidade do amor que dá antes de receber, superando, portanto, a solidariedade genérica. Chiara Lubich, no mesmo pensamento, defendia a tese de "ser o primeiro a amar". 


\section{O papel do princípio da fraternidade no contexto de crise, tragédias e rupturas}

Vargas (2018, p. 10) defende que: "viver o paradigma da fraternidade é ser capaz de gerar "encontro", este entendido como maior que a simples soma dos participantes, pois gera um algo mais, uma ambiência serena e feliz, campo fértil para o alargamento relacional e de confiança recíproca, um verdadeiro sentimento de pertença familiar muito além de laços de consanguinidade.

Aqui temos uma pista relevante para compreender a importância da fraternidade em contexto de crise, tragédia ou ruptura, qual seja a capacidade de "gerar encontro", não apenas físico, presencial, mas um estado mais profundo de comunhão (comum união), neste viés, fazse necessário colocar-se no lugar do outro, estar interessado em sua condição. Fonseca (2018, p. 159) identifica diversas crises nas quais a sociedade brasileira encontra-se imersa e propõe ser "chegada a hora de resgatarmos os valores da ética, do Direito e da Democracia, com a construção de um novo paradigma de justiça. Uma justiça inclusiva e fraterna”.

Nas crises mais profundas que a humanidade vivenciou na sua história, há exemplos concretos na promoção de ações solidárias e fraternas nas relações entre as pessoas. Uma relação humana baseada na fraternidade exige o protagonismo de todos os envolvidos em um plano horizontal, proativo e atuante (liberdade), bem como equivalência entre todos permeada de reciprocidade, pois os agentes compreendem não possuir apenas direitos, mas também obrigações (igualdade), é preciso relembrar que há, na fraternidade, um comprometimento, um dever, mas este não é suportado por uma parte dos envolvidos, mas por todos. Considerar-se irmão é comprometedor de fato. A solidariedade é considerada uma expressão da fraternidade, mas apenas e tão somente uma face, um aspecto, uma expressão parcial.

Deste modo, segundo Pizzolato (2008, p. 113), a fraternidade tem o condão de provocar o comportamento individual a responsabilizar-se pela condição em que se encontra o irmão. Segundo Souza Silva e Souza Neto (2011): “Na alteridade, significando pensar no 'outro', não como inimigo ou obstáculo a ser vencido ou derrotado, mas como alguém que nos completa, que nos amadurece que nos lembra que não somos competentes sozinhos". Neste sentido, Resta (2004) expõe: “A fraternidade recoloca em questão a comunhão de pactos entre sujeitos concretos com as suas histórias e as suas diferenças, não com os poderes e as rendas de posições que escondem o egoísmo". 
Pode parecer contraditório, mas diversas conquistas logradas pela humanidade surgiram durante ou depois de grandes crises, tragédias ou rupturas. A própria fraternidade como princípio político surgira no contexto da Revolução Francesa em 1789, os direitos humanos encontraram seu reconhecimento mais alargado e pactuado após a II Guerra Mundial, com a Declaração Universal dos Direitos Humanos (1948), a própria gênese da Organização das Nações Unidas (ONU) com a Conferência de São Francisco em 1945, o ataque às torres gêmeas que desencadeou ações solidárias e fraternas nos cidadãos americanos, apenas para citar alguns.

Não precisamos voltar muito no tempo para percebermos esta realidade, pois no momento atual, qual seja 2020, vivenciamos uma pandemia global causada pela COVID-19 a qual desencadeou uma crise sem precedentes na história recente da humanidade. Cada subsistema social procurou contribuir com respostas concretas arrimadas na ação fraterna.

No Direito, as mais variadas espécies normativas foram criadas no sentido de disciplinar as relações jurídicas neste período de pandemia, quais sejam normas flexibilizando licitações para uma maior agilidade na compra de insumos médicos de combate ao vírus.

A lei $n^{\circ}$ 14.010/20 dispondo sobre o Regime Jurídico Emergencial e Transitório das relações jurídicas de Direito Privado (RJET) no período da pandemia do coronavírus (Covid19), ou seja, disciplinando as relações jurídicas de direito privado na relação consumerista, dos contratos de locação, etc.

A Agência Nacional de Energia Elétrica (Aneel) com a Resolução n 878 proibindo o corte no fornecimento de energia elétrica para todos aqueles que não conseguiram pagar a conta de luz durante o período da pandemia do novo coronavírus. Em relação à distribuição de água e proibição no corte do fornecimento, enquanto durar a pandemia, normas estaduais e decisões judiciais asseguram este direito.

O socorro aos hipossuficientes materializado nos auxílios emergenciais; a proteção legal na manutenção dos empregos; até mesmo a possibilidade na aprovação de uma emenda constitucional alterando a data das eleições para proteger a saúde dos cidadãos.

Mesmo aquelas pessoas que são discriminadas socialmente, quais sejam os apenados, contaram com a sensibilidade do olhar fraterno, seja dos demais cidadãos, seja das Instituições preocupados com as condições sanitárias dentro das unidades prisionais. Também o Conselho Nacional de Justiça (CNJ) com a publicação da Recomendação $n^{\circ} 62$, com medidas no sentido de conter o avanço da pandemia do novo coronavírus no sistema carcerário brasileiro reavaliando as penas e medidas socioeducativas, bem como relaxando a pena para o 
cumprimento de prisão domiciliar ou até mesmo concessão de liberdade provisória. A fraternidade está presente quando se verifica o rol dos beneficiários quais sejam os presos provisórios, os crimes cometidos sem violência, bem como os encarcerados que pertencem ao grupo de risco. O CNJ defendeu a importância dessas medidas para mães de crianças, gestantes e lactantes. No HC 563.142 o Ministro do Superior Tribunal de Justiça (STJ) Reynaldo Soares da Fonseca substituiu a prisão preventiva por prisão domiciliar, em razão da condição de saúde debilitada do acusado, atendendo assim à supramencionada Recomendação do CNJ.

Vale mencionar a decisão da suspensão do recesso parlamentar tanto no Congresso Nacional, nas Assembléias Legislativas e Câmaras Municipais para continuarem atuando em defesa dos direitos fundamentais constitucionalmente estabelecidos.

Em meio à tragédia pandêmica nivelando todos os seres humanos, os investimentos na saúde não foram vistos como gasto público inócuo, mas como um meio de tentar salvar a vida de muitos, sem distinção.

Neste sentido destacamos a atuação dos 3 (três) Poderes da República Federativa do Brasil buscando concretizar o preâmbulo e o art. $3^{\circ}$, I da Constituição Federal neste tempo de crise pandêmica, cada um adstrito à sua competência, o Executivo na agilidade das medidas provisórias, o Legislativo na fiscalização e produção de leis e emendas e o Judiciário assegurando os direitos fundamentais por meio de suas decisões além de controlar os demais Poderes sempre com arrimo nas normas da Carta Magna. Aliás, o Judiciário sempre conferiu ao direito fundamental à saúde, um tratamento diferenciado:

É no direito fundamental social prestacional à saúde que encontramos as mais profícuas decisões no sentido da concretização. O Judiciário mostra-se árduo defensor desse direito e o correlaciona com a dignidade de pessoa humana [...] Inúmeros são os julgados que corroboram o dantes asseverado tanto nos Tribunais de Justiça, quanto nos Tribunais Superiores, seja condenando o Estado ao fornecimento de medicamentos (os mais variados e independentemente do valor dos mesmos), seja determinando o custeio pelo Estado de tratamento no exterior quando tal procedimento não exista no país ou adotando outras medidas atinentes ao direito à saúde. (ANDRADE, 2011, p. 11).

Em meio ao caos sanitário, econômico, social, político, etc, ações de solidariedade e fraternidade multiplicam-se também entre as pessoas na horizontalidade das relações, tais como a mobilização espontânea para ajudar pessoas em estado de vulnerabilidade social, apoio psicológico, distribuição de alimentos, doação de produtos de higiene pessoal, consultas médicas gratuitas e o trabalho incessante dos profissionais da saúde. Tal situação nos faz reconhecer o outro na sua condição humana gerando uma ideia de preocupação e cuidado recíproco. 
Como dissemos, nas situações extremas surge a solidariedade e a fraternidade no sentido de corresponsabilidade com o outro, o ser humano é por natureza coletivo e esta condição aflora com mais intensidade diante da fragilidade humana, na busca pela sobrevivência do gênero humano percebe-se que juntos, no plano coletivo, são mais fortes e capazes de superar as adversidades.

A fraternidade promove uma interação autêntica ao oportunizar o encontro de diferentes, mas que se reconhecem em mesmo patamar, assim vislumbramos que numa sociedade onde permita tal concepção a fraternidade, o agir fraterno, será uma resposta ao desejo permanente da humanidade de reconhecer-se como irmão, possibilitando o fortalecimento do ser humano.

\section{Considerações finais}

Consideramos que a ação fraterna propicia ao ser humano a responsabilidade do cuidado com o outro e com o mundo em que vive, há um compromisso que se estabelece nas relações e nas ações de cada indivíduo mesmo na sua diversidade de pensamento e diferentes concepções de mundo sendo de extrema importância para a sociedade contemporânea, o agir fraterno.

A fraternidade é um princípio norteador em vários âmbitos, pode ser relacionada à política, saúde, economia, sociologia, filosofia, teologia, Direito. Significa um passo além da solidariedade no reconhecimento recíproco entre pessoas livres e iguais, constitui-se em resposta para grandes dilemas na promoção do encontro.

O conceito de Fraternidade traz em si a potencialidade da plena cidadania entre os seres humanos, quando se reconhecem como iguais, irmãos, fraternos, que fazem parte de uma mesma família.

A palavra fraternidade contém na sua essência o sentido de corresponsabilidade, de interdependência e gera relacionamentos autênticos que possibilitam a concretização do bemcomum, de sentir-se partícipe da grande família humana, é voltada à construção do ut omnes no sentido do reconhecimento do outro que é diferente de mim, mas ao mesmo tempo igual a $\operatorname{mim}$.

Para garantir um ambiente de Paz que contraponha as crises vividas pelo ser humano na atualidade, a fraternidade não pode ser vista apenas como um sentimento, mas um princípio 
norteador das relações humanas onde o bem comum perpasse na vivência, no agir de cada indivíduo e tenha como fim o bem-estar da coletividade.

No Direito, as mais variadas espécies normativas foram criadas no sentido de disciplinar as relações jurídicas neste período de pandemia. Destacamos a atuação dos 3 (três) Poderes da República Federativa do Brasil buscando concretizar o preâmbulo e o art. $3^{\circ}$, I da Constituição Federal neste tempo de crise pandêmica, cada um adstrito à sua competência. Em meio ao caos sanitário, econômico, social, político, ações de solidariedade e fraternidade multiplicaram-se também entre as pessoas na horizontalidade das relações, demonstrando que a fraternidade não é esquecida, mas ao contrário, potencializada em tempos de crise.

\section{REFERÊNCIAS}

ANDRADE, Ana Paula Cavalcante Luna de. A ética do discurso como possível meio de integração social: caminhos de fraternidade. In: BAQUERO, Javier; NUIM, Susana (orgs.) Memorias del VI Seminario Internacional sobre estudios de fraternidad: perspectivas de lo político desde la fraternidad. Caruaru: Editora ASCES, 2018.

ANDRADE, Fernando Gomes de. Direitos de fraternidade como direitos fundamentais de terceira dimensão: aspectos teóricos e aplicabilidade nas decisões do Supremo Tribunal Federal brasileiro. In: Revista Amicus Curiae, UNESC. V.8, N.8 (2011), 2011.

BAGGIO, Antonio Maria. La fraternidad antagonista: la interpretación freudiana y la fundación de la sociedade igualitaria y conflictiva. In: BAGGIO, Antonio Maria (org.). La fraternidad em perspectiva política: exigências, recursos, definiciones del princípio olvidado. Buenos Aires: Ciudad Nueva, 2009.

BAGGIO, Antonio Maria. La fraternità: una nuova categoria nello spazio pubblico. In: OLIVEIRA, Olga Maria Boschi Aguiar de; VERONESE, Josiane Rose Petry. Direitos na pós-modernidade: a fraternidade em questão. Florianópolis: Funjab, 2011.

BARZOTTO, Luís Fernando. Fraternidade: uma aproximação conceitual. In: MACHADO, Carlos Augusto Alcântara; JABORANDY, Clara cardoso Machado; BARZOTTO, Luciane Cardoso. Direito e Fraternidade: em busca de concretização. Aracaju: EDUNIT, 2018.

BERGOGLIO, Jorge Mário; SKORKA, Abraham; FIGUEROA, Marcelo. A solidariedade. Sandra Martha Dolinsky (Trad.) São Paulo: Benvirá, 2010.

CARTA ENCÍCLICA CARITAS IN VERITATE do sumo pontífice

BENTO XVI'. Disponível em: http://www.vatican.va/content/benedict$\mathrm{xvi} / \mathrm{pt} / \mathrm{encyclicals} / \mathrm{documents} / \mathrm{hf}$ _ben-Xvi_enc_20090629_caritas-in-veritate.html, acesso em 26 de Maio de 2020. 
CERVIÑO, Lucas. A fraternidade em conflito e o conflito fraterno: contribuições a partir da interculturalidade. In: LOPES, Paulo Muniz (org.). A fraternidade em debate: percurso de estudos na América latina. São Paulo: Cidade Nova, 2012.

COX, Cristián. El princípio de fraternidad em los valores, instituciones y relaciones sociales de la educación escolar latinoamericana. In: MARDONES, Rodrigo. Fraternidady educación: um princípio para la formación ciudadana y la convivencia democrática. Buenos Aires: Ciudad Nueva, 2012.

FIORES, Stefano; GOFFI, Tullo. Dicionário de Espiritualidade. São Paulo: Paulinas, 1989. LUBICH, Chiara. Discurso em Innsbruck (Áustria), no Congresso "1000 cidades para a Europa (Novembro de 2001).

MACHADO, Carlos Augusto Alcântara. A Fraternidade como categoria jurídica: fundamentos e alcance. Curitiba: Appris, 2017.

MARDONES, Rodrigo. Hacia uma precisión conceptual de la fraternidad política. In: BARRENECHE, Osvaldo. (org.). Estudios recientes sobre fraternidad: de la enunciación como princípio a la consolidación como perspectiva. Buenos Aires: Ciudad Nueva, 2010.

MARDONES, Rodrigo. Por uma exatidão conceitual da fraternidade política. In: LOPES, Paulo Muniz (org.). A fraternidade em debate: percurso de estudos na América latina. São Paulo: Cidade Nova, 2012.

PIZZOLATO, Filippo. A fraternidade no ordenamento jurídico italiano. In: BAGGIO, Antônio Maria. O princípio esquecido. São Paulo: Cidade Nova, 2008.

RESTA, César. O Direito Fraterno. Tradução Sandra Regina Martini Vial (Coord.). Santa Cruzdo Sul - RS: EDUNISC, 2004.

ROPELATO, Daniela. Notas sobre participação e fraternidade. In:BAGGIO, Antonio Maria (Org.). O princípio Esquecido I: A fraternidade na reflexão atual das ciências políticas. Vargem Grande Paulista, SP: Editora Cidade Nova, 2008.

SOUZA SILVA. Juliana. SOUZA NETO, Samuel de. Projeto 'Escola de Educadores': a fraternidade como prática pedagógica. Disponível em http://www.efdeportes.com/efd91/ee.htm, acesso em 28.10.2018.

VARGAS, José Arturo Luna. La persona, comunicación política y ética. Puntos claves para la construcción de lo público. In: BAQUERO, Javier; NUIM, Susana (orgs.) Memorias del VI Seminario Internacional sobre estudios de fraternidad: perspectivas de lo político desde la fraternidad. Caruaru: Editora ASCES, 2018.

ROSSETTO, Geralda Magella de faria; VERONESE, Josiane Rose Petry. Fraternidade e Unidade: paradigmas ao Pensamento contemporâneo. In: VERONESE, Josiane Rose Petry; OLIVEIRA, Olga Maria Boschi Aguiar (orgs). Direito, justiça e fraternidade. Rio de Janeiro: Lumen Iuris, 2017.

VERONESE, Josiane Rose Petry; OLIVEIRA, Olga Maria Boschi Aguiar; MOTA, Sérgio Ricardo Ferreira (orgs). O Direito revestido de fraternidade. Florianópolis: Insular, 2016. 